\title{
A POLÍTICA DO TABLETE EDUCACIONAL NO ENSINO DE INGLÊS EM ESCOLAS DO ESTADO DO PARANÁ ${ }^{1}$
}

Paulo Henrique ESPURI

Pós- Graduação em Estudos da Linguagem - Universidade Estadual de Londrina

\begin{abstract}
RESUMO: Desenvolvimentos tecnológicos na área de informação e comunicação têm gerado inúmeras ferramentas e desencadeado práticas sociais nas quais seus usos são considerados indispensáveis. Por esse motivo, são também objeto de políticas governamentais que buscam ampliar seu acesso a diversas camadas da população. Este trabalho objetiva analisar criticamente a política do tablete educacional, tanto em relação aos textos oficiais que a representam quanto no que se refere à sua realização em escolas públicas do Estado do Paraná. A fim de alcançar o referido objetivo, a pesquisa apoia-se nos estudos de Ball (2012), Ball, Braun e Maguire (2012) e Mainardes (2006) acerca de políticas educacionais, bem como nas contribuições de Selwyn $(2010,2013)$ relativas à análise crítica de TIC em contextos educacionais. Os dados (textos oficiais que representam a política, 226 respostas de professoras e professores de diversas disciplinas e regiões do Estado do Paraná a um questionário e 10 entrevistas semiestruturadas com professoras de inglês) foram analisados com base no referencial supracitado. Os resultados preliminares apontam conflitos entre os propósitos da política e as ações empreendidas na sua realização em escolas públicas no Estado do Paraná.
\end{abstract}

Palavras-chave: Tecnologias de informação e comunicação; política educacional; tablete educacional.

\begin{abstract}
Technological developments in the field of communication and information have created several tools, which, in turn, have promoted social practices in which their uses are essential. For this reason, they have been the object of government policies aimed at promoting its wider access to a larger population. This paper aims at analyzing critically a policy that encourages the use of tablets in classrooms, not only in relation to official texts that represent it, but also considering its enactment in public schools located in the State of Paraná. In order to achieve this objective, this research is based on Ball (2012), Ball, Braun and Maguire (2012) and Manairdes (2006) in terms of education policies, as well as on Selwyn $(2010,2013)$ as for critical analysis of ICT in educational contexts. The data (official texts that represent the policy, 226 teachers from different regions of Paraná who answered an online survey and 10 semi-structured interviews with English teachers) were analyzed based on the studies above. Preliminary results indicate conflicts between the purpose of the policy and its enactment in public schools located in Paraná State.
\end{abstract}

Keywords: Information and communication technologies; educational tablet policy; educational tablet.

\footnotetext{
${ }^{1}$ Este estudo deriva de uma dissertação em andamento, financiada pela Capes e Fundação Araucária.
} 


\section{Introdução}

"Tablet muito ruim, lento, pesado. Internet não funciona na escola do campo"

(Professora da educação básica)

A importância do acesso às novas tecnologias de informação e comunicação (TIC) nos contextos social, acadêmico e escolar por parte de professores e estudantes das escolas públicas deu origem à política do tablete educacional. O Ministério da Educação do Brasil, por meio do Programa Nacional de Tecnologia Educacional (ProInfo Integrado), e com financiamento via Fundo Nacional de Desenvolvimento Educacional - FNDE, promove a distribuição de tabletes a escolas (BRASIL, 201-), mediante os seguintes critérios: a) ser escola urbana de ensino médio; b) ter Internet banda larga e laboratório do Programa Nacional de Tecnologia Educacional (ProInfo); e c) disponibilizar rede sem fio (wi-fi). De acordo com o FNDE, o uso do tablete educacional deve ser "articulado à distribuição dos equipamentos tecnológicos nas escolas e à oferta de conteúdos e recursos multimídia e digitais (BRASIL, 201-).

Essa política em sido objeto de estudos e uma busca sem limitação de ano de publicação no Google Acadêmico ${ }^{2}$, a partir das palavras-chave "tablete" e "tablete educacional", permitiu a identificação de 53 trabalhos. Entre eles encontram-se 5 artigos e 2 monografias que tratam especificamente da política do tablete educacional, conforme demonstra o Quadro xxx :

Autor (es)

Abreu

Nogueira

Freire

Nascimento

\& $\quad 2014$

\& 2013

\&
e uma escola privada no Distrito Federal

Neves

Cardoso,

Nunes

2013 Uso de tablets na educação na percepção de professores da educação profissional

capacitação de professores para o uso do tablet educacional.

\& 2013 Os desafios do uso do tablet pelos professores do ensino médio das escolas públicas do Distrito Federal

Cruz \& Neri
2014 A inserção de tablets em escolas da rede pública estadual na cidade de
Objetivos

Analisar o uso de tabletes em duas escolas do Distrito Federal que adotaram o uso deste aparato tecnológio em seu projeto educativo

Apresentar um relato de experiência sobre a capacitação de professores para o uso do tablete educacional recebido pelo governo da Paraíba.

Investigar os desafios do uso do tablete em sala de aula.

Analisar as possibilidades de uso de tablets como apoio ao processo de ensino aprendizagem com base na percepção dos docentes de educação profissional, professores do IFES - campus Serra

Analisar a percepção de alunos e professores sobre a utilização

\footnotetext{
${ }^{2}$ Realizada entre 2 e 4 de março de 2015.
} 
Petrolina-PE

Giacomazzo \& 2014 A implantação do tablet educacional Fiuza

Padilha

2014

O professor de Matemática da Educação Básica e o processo de apropriação das tecnologias móveis

Real, Tavares \& 2013 Formação de Professores para o Uso Picetti

dos tabletes educacionais

Investigar o perfil dos professores e analisar a inserção dos tablets educacionais a partir da percepção dos contemplados nessa política pública federal e o uso que estão fazendo do recurso.

Identificar e analisar como um grupo de professores de Matemática da Educação Básica da rede pública do Estado de São Paulo se apropria das Tecnologias Digitais Móveis (tablets) para ensinar função polinomial do $1^{\circ}$ grau.

Evidenciar as ações realizadas pelo Núcleo de Tecnologia em Educação do Rio Grande do Sul (NTE/RS) para distribuição e uso pedagógico dos Tablets educacionais.

Quadro 1: estudos sobre o tablete educacional realizado entre 2 e 4 de março de 2015

Tais estudos apontaram questões que já vinham sendo objeto de nossas preocupações, pois já tínhamos lido comentários negativos a respeito dessa política em uma comunidade virtual de professoras e professores de escolas públicas do Paraná ${ }^{3}$. Docentes participantes dessas comunidades apontaram problemas na realização da política, tanto em relação à qualidade do próprio dispositivo e sua função pedagógica, quanto em relação à sua distribuição. A partir da leitura dos artigos, postagens e comentários que problematizavam aspectos da política do tablete educacional, decidimos desenvolver uma pesquisa que pudesse lançar um olhar sobre essa política em escolas públicas no Estado do Paraná, uma vez que os trabalhos supracitados foram desenvolvidos em outros estados brasileiros.

\section{Fundamentação teórica}

Para empreender uma análise crítica da política do tablete educacional em escolas públicas paranaenses, ancoramos esse estudo em Selwyn (2013), quando o autor defende que uma reflexão crítica sobre TIC contemplaria ir para além de sua distribuição em instituições de ensino sem reflexões posteriores quanto a forma que as TIC de fato impactam processos de ensino e aprendizagem. Como Selwyn (2013), acreditamos que, independentemente de como os discursos pró-TIC se posicionam, uma análise crítica sobre elas deve ser norteada por perguntas como a) quais usos das TIC têm de fato ocorrido no contexto educacional? Por que

\footnotetext{
${ }^{3}$ https://www.facebook.com/groups/184183368332553/ https://www.facebook.com/groups/ProfPRsemcensura29abril/ https://www.facebook.com/groups/professoreseescolasdeingles/ https://www.facebook.com/groups/213331702107907
} 
esses usos das TIC no contexto educacional ocorrem dessa forma? Pretendemos, por meio de nossas análises responder a tais perguntas, que compõem os objetivos dessa pesquisa. Além disso, tais reflexões serão abordadas sob o prisma do ciclo de políticas (policy cycle) quanto à realização da política do tablete educacional.

Com base em estudos de Stephen Ball e Richard Bowe, Mainardes (2006) defende que a abordagem do ciclo de políticas pode lançar um olhar mais cauteloso sobre a natureza complexa e controversa das políticas educacionais, uma vez que considera os diferentes contextos que contribuem para sua realização. Os contextos seriam três, a saber: a) contexto de influência, b) contexto da produção de textos; e c) o contexto da prática. O contexto de influência é aquele onde se localizam os discursos que justificam a política, à medida que grupos de interesse e meios de comunicação se mobilizam e atribuem legitimidade a tais discursos.

Em uma relação definida como simbiótica e complexa por Mainardes (2006), o contexto de influência relaciona-se ao contexto de produção dos textos que representam a política, o que evidentemente faz com que ambos os contextos supracitados estejam vinculados ao da prática. As influências acabam ganhando contornos e assumem formas de textos oficiais, geralmente ligados à linguagem e interesses dos sujeitos em geral. Como textos representantes da política, o autor considera vídeos, pronunciamentos, comentários formais e informais e textos políticos oficiais. Com base em Ball, Maguire e Braun (2006) e Mainardes (2006), o contexto da prática é uma instância de negociações em que os textos oficiais são interpretados por sujeitos dotados de agência na realização da política. Tais textos podem assumir diferentes significados à medida que integram a comunidade escolar em um complexo processo de significação em face de dimensões do contexto da prática (BALL; MAGUIRE; BRAUN, 2012). Em nossas análises trataremos de aspectos presentes no contexto de influência e produção de textos, para que, posteriormente, possamos refletir sobre o contexto da prática a partir de nossos dados.

\section{Objetivos}

Esta pesquisa tem por objetivo geral analisar criticamente a realização da política do tablete educacional em escolas públicas do Paraná, especialmente no que diz respeito ao ensino de língua inglesa. São objetivos específicos: a) apresentar a política do tablete educacional e refletir sobre percepções de professoras e professores da escola pública no Paraná quanto essa política; b) identificar os usos do tablete educacional, suas motivações e consequências; e c) refletir sobre os contextos de influência, produção de textos e prática da política do tablete educacional.

\section{Metodologia}

Os dados da entrevista serão analisados a sob as lentes da Grounded Theory (CHARMAZ, 2006). A autora define o método como um conjunto de princípios e práticas cujo objetivo é identificar e compreender categorias capazes de construir teorias. Sob tais lentes, nosso trabalho propõe identificar aspectos presentes nos discursos das participantes que possam responder às perguntas de pesquisa.

\subsection{Contexto de influência}


Para atender ao objetivo de apresentar a política em seus contextos de influência e de produção de textos, discorreremos sobre as possíveis influências sobre políticas de inserção de TIC na escola pública e, posteriormente, apresentaremos textos que representam a política do tablete educacional. A inevitabilidade e benefícios das TIC parecem estar subjacentes às preconizações de órgãos transacionais ${ }^{4}$, que reforçam percepções pró-TIC que podem nos levar a ignorar suas implicações práticas e situadas no contexto educacional. Libâneo (2016), ao considerar as políticas educacionais e suas relações com tais órgãos, defende que

No âmbito das políticas oficiais, a pesquisa tem mostrado que as políticas educacionais aplicadas à escola nas últimas décadas têm sido influenciadas por orientações dos organismos internacionais, as quais produzem um impacto considerável nas concepções de escola e conhecimento escolar e na formulação de currículos (LIBÂNEO, p.40, 2016).

No site da UNESCO, por exemplo, há sugestões em relação às tecnologias em um texto intitulado Brasil no rumo da inclusão. Assim, percebemos que subjacentes a esse discurso estão valores segundo os quais as TIC trazem potencialidades para a inclusão e equidade social, já que os sujeitos que dominam tal conhecimento têm acesso a diferentes espaços discursivos, inclusive ao mercado de trabalho:

A maioria dos brasileiros computadorizados (65\%), por sua vez, tem curso superior completo e se situa entre as classes A e B (61 e 65\%), C $(51,2 \%)$, deixando um índice bem abaixo para as classes D-E (30\%). A faixa etária predominante entre esses mesmos usuários vai de 16 a 24 anos (23\%); apenas $8 \%$ são pessoas acima de 60 anos. Os dados permitem delinear o perfil do indivíduo incluído na sociedade da informação no Brasil: ele é jovem, pertence às classes mais abastadas, vive num lar com TV, rádio, celular e videogame, sabe usar a tecnologia e utiliza conexão rápida à Internet (UNESCO, 2008, p.2).

No entanto, a Pesquisa Nacional por Amostra em Domicílios (PNAD), realizada em 2013, ainda nos permite refletir sobre a baixa incidência de acessos à Internet no Brasil. Nessa pesquisa, o percentual de acesso à Internet ocorre em $16 \%$ das residências no Maranhão e $18,7 \%$ no Piauí. As amostras ilustram profundas limitações de conectividade, especialmente no norte e nordeste, regiões com grande incidência de pessoas economicamente vulneráveis. Em contrapartida, o Distrito Federal apresentou o maior percentual de acesso, com 66,7\%, ficando em segundo lugar a região metropolitana de São Paulo, com 62,4\% de acessos residenciais. Já o Estado do Paraná, um dos que possuem maior representatividade econômica no país, possui $47 \%$ de suas residências conectadas, percentual ainda baixo, mas significativamente maior do que os dados mostram em relação as regiões Norte e Nordeste .

A partir desses dados, tentamos ilustrar a reflexão de Selwyn (2008), que articula a relação às TIC e com estruturas hegemônicas do século XX. As regiões demográficas brasileiras mais vulneráveis economicamente são aquelas que possuem menos acesso e, consequentemente, apresentam limitações no que toca o discurso tão difundido sobre o

\footnotetext{
${ }^{4}$ Organização das Nações Unidas para a Educação, Ciência e Cultura (UNESCO), O Fundo Monetário Internacional (FMI), Banco Mundial e Organização para a Cooperação e Desenvolvimento Econômico (OCDE).
}

${ }^{5}$ http://ibge.gov.br/home/estatistica/populacao/acessoainternet2013/default.shtm 
rompimento das fronteiras ${ }^{6}$, acesso a (construção de) conhecimento e possibilidades de agência. Novamente, reforçamos a ideia de que ainda que ampliado, acreditamos fortemente que o acesso não é o único fator responsável pelo uso significativo das TIC.

Braga (2010), por exemplo, defende que os letramentos digitais são importantes no sentido de permitir que o acesso às novas práticas sociais da contemporaneidade promova inclusões na chamada sociedade do conhecimento. Os analfabytes, termo utilizado pela autora para se referir às pessoas que ficam à margem em termos de TIC, pode ser uma ressignificação do termo analfabeto do passado. Isso pode ocorrer também não só necessariamente pelo (não) acesso às TIC em si, mas também pelo não domínio de conhecimentos e diferentes práticas sociais relevantes para essa nova era, o que sempre foi um fator ligado ao poder e domínio ao longo de nossa história.

Acreditamos que as desigualdades do século XXI parecem não estar tão distantes daqueles presentes no século XX. Selwyn (2008) ao descrever seu contexto de pesquisa enfatiza a relação entre os usos das TIC e fatores tais como gênero, localização geográfica, escolaridade, raça, renda, idade. Não obstante, em uma suposta nova roupagem e a partir de um ponto de vista econômico em que o termo TIC torna-se um sinônimo para desenvolvimento, as influências de seus usos acabam permeando exigências de novas habilidades diante do cenário capitalista, neoliberal e globalizado do século XXI. Tais demandas não poderiam deixar de fazer parte de processos educacionais, cujos pesquisadores têm se debruçado sobre o tema no sentido de compreender os ganhos trazidos por elas no processo de ensino e aprendizagem. Tal destaque do tema parece derivar de pressões micro e macro para que escolas preparem indivíduos a fim de que lidem com os desenvolvimentos tecnológicos recentes que apostam na mobilidade e na informação digital.

Ao navegarmos no site do Banco Mundial, outro órgão transnacional que impacta políticas educacionais de países ditos emergentes, percebemos que o uso de recursos tecnológicos é mais cautelosamente associado a tentativas de desenvolvimento econômico e social. Em artigos como smartphones podem aprimorar a qualidade do ensino no Haiti ${ }^{7}$ ? e como a tecnologia pode influenciar a empregabilidade?, as TIC parecem ser vistas (pelo menos preliminarmente) como soluções para problemas de natureza econômica ${ }^{8}$ em países emergentes.

Entretanto, indo ao encontro do que acreditamos, o próprio órgão, nos dois artigos supracitados, reconhece que o uso das TIC requer mais do que a distribuição de dispositivos para o alcance dos objetivos que acredita serem importantes. A experiência de uso das TIC para o controle de faltas de professores e qualidade de ensino, por exemplo, fracassou pela falta de infraestrutura do país emergente no desenvolvimento desse projeto em parceria com o Ministério da Educação haitiano. De acordo com o Banco Mundial, a lição aprendida com essa experiência foi de que as coisas não são tão simples quanto parecem.

A relação entre uma possível agenda capitalista, neoliberal e globalizada e as TIC vai se construindo à medida que os artigos presentes no website do órgão ilustram os possíveis benefícios de tais recursos em termos de desenvolvimento a partir de um ponto de vista

\footnotetext{
${ }^{6}$ https://olc.worldbank.org/content/welcome-Internet

${ }^{7}$ https://olc.worldbank.org/content/haiti-can-smartphones-make-schools-better

${ }^{8}$ https://olc.worldbank.org/content/will-digital-revolution-help-or-hurt-employment-adaptation-key-realizingjob-gains
} 
econômico ${ }^{9}$. É possível perceber que o Banco Mundial acredita que os países que melhor se adaptarem à revolução digital possuem mais chances de se destacarem no cenário econômico. Para aquele Banco, em 2016, as 125 milhões de crianças que agora estão na idade para se inserirem no sistema de ensino precisam dominar habilidades que outrora não eram exigidas para serem competitivas e conseguirem bons trabalhos.

Essas percepções sobre as TIC em relação ao aumento de indicadores para uma competição global sob um posto de vista educacional e econômico também são construídas em textos e ações da OCDE. A desenvolvedora do teste PISA afirma em seu site que objetiva, por meio de sua riqueza de informação sobre uma gama de assuntos, ajudar os governos a promoverem a prosperidade e lutar contra a pobreza através do crescimento econômico e da estabilidade financeira dos países. Ainda acordo com o Instituto Ayrton Senna, também parceiro da OCDE, as estratégias do órgão são:

[...] a promoção de fóruns para troca de experiências e busca de soluções comuns entre governos, a análise e comparação de dados para a compreensão dos fatores envolvidos em mudanças econômicas, sociais e ambientais e o estabelecimento de padrões internacionais para balizar uma extensa gama de atividades humanas, desde a agricultura até a educação ${ }^{10}$.

O PISA (Programme for Internacional Student Assessment), teste feito por alunos de 15 anos, conta atualmente com mais de 70 países participantes e configura-se como um parâmetro internacional de comparação entre processos de ensino-aprendizagem e possivelmente acaba incitando reflexões para o ensino e TIC em face de nossos resultados tão baixos. Entre os 65 países participantes do PISA, o Brasil ficou em 2012 abaixo da sexagésima posição, atrás outros de países na América Latina como o Chile, México, Uruguai e Costa Rica. Confrontando tais dados com o levantamento do PNAD, tais resultados podem sugerir que os baixos índices em relação ao desempenho dos brasileiros no teste possam estar relacionados aos (não) usos das TIC nas escolas e fora de seus muros. Um questionário opcional acerca do contato de estudantes com TIC foi disponibilizado no próprio processo de realização do teste, embora seu resultado não tenha sido divulgado pelo órgão.

Ao inserir tal temática no teste, acreditamos que isso possa significar que as TIC são consideradas importantes em termos educacionais para a OCDE. Ao analisarmos os objetivos da organização, inferimos que ela talvez considere as TIC elementos relevantes para o desenvolvimento econômico e social. Ainda, como previsto na publicação dos resultados de 2009, os posteriores testes do PISA de fato consideraram as TIC como fator de destaque: o teste de 2012 trouxe o já mencionado questionário e avaliação eletrônica feita em computadores, ao passo que o de 2015 foi realizado em sua totalidade por meio deles, o que pode evidenciar a importância das TIC do letramento digital.

Ademais, percebemos também a percepções sobre TIC no site do FMI, órgão criado em uma conferência da ONU em Bretton Woods, New Hampshire, Estados Unidos, em julho de 1944. Na época de sua criação, os 44 países na conferência buscaram construir um quadro de cooperação econômica para evitar que a concorrência desvalorizações que haviam contribuído para a Grande Depressão da década de 1930. Na página web do FMI, uma foto de crianças negras utilizando computadores é utilizada ao fundo para descrever seus objetivos: uma fundação composta por 188 países que trabalha para aprimorar a cooperação

\footnotetext{
${ }^{9}$ https://olc.worldbank.org/content/how-tech-hubs-are-helping-drive-economic-growth-africa

${ }^{10}$ http://educacaosec21.org.br/quem-somos/ocde/
} 
monetária, estabilidade financeira, o comércio internacional ${ }^{11}$. Além disso, segundo o site, as ações do FMI gravitam em torno da promoção da alta taxa de emprego, do desenvolvimento econômico sustentável e da redução de pobreza pelo mundo ${ }^{12}$. Acreditamos que tais instituições transnacionais, ao relacionarem seus objetivos ao desenvolvimento sob uma perspectiva econômica e visibilidade às TIC, acreditam que tais dispositivos podem trazer consigo oportunidades de desenvolvimento.

\subsection{A política do tablete educacional em discursos oficiais}

A política do tablete educacional se insere em uma política mais abrangente de acesso a tecnologias digitais. Entretanto, por limitações de espaço, nos restringiremos à distribuição dos tabletes e seus usos no cotidiano escolar. Uma das vozes oficiais esteve refletida na fala do então Ministro da Educação, Aloizio Mercadante, que afirmava que o tablete traria a possibilidade de assistir vídeos educacionais da Fundação Khan ${ }^{13}$, uma ONG educacional que oferta materiais para estudo por meio das TIC. Em entrevista, o Ministro afirmou a intenção de utilizar os vídeos presentes na plataforma em 600 mil tabletes educacionais para que professores pudessem assistir aulas e terem parâmetros de boas aulas e práticas didáticas exitosas. Ainda, recursos seriam disponibilizados em laboratórios do Proinfo, de modo que os alunos pudessem estudar em momentos em que não estão na sala de aula.

Ainda em 2013, ao ser questionado ${ }^{14}$ sobre o projeto pedagógico que se articularia com a política do tablete, o Ministro da Educação afirmou que ofertaria os portais com aulas e informações, que, de acordo com nosso entendimento se constituem de: coleções de educadores, todas as aulas do professor Khan (referência à Salman Khan, fundador da plataforma mencionada na entrevista acima contemplando conteúdos de Física, Química, Matemática e Biologia), todo conteúdo do portal do professor, todo conteúdo o material da TV Escola, todos os periódicos (revistas e jornais) poderão ser acessadas pelo tablete, assim como revistas especializadas em educação. Com 60 mil portais digitais, um tablete de 10 polegadas será distribuído e um projetor digital serão distribuídos. O professor receberá um tablete de 7 polegadas para projetar os conteúdos.

O ministro ainda disse que todas as salas de Ensino Médio possuiriam um tablete, chegando o número total a 78 mil unidades. Com essa entrevista, o Ministro da Educação aponta para uma modernização da escola brasileira, garantindo que as escolas disporiam de TIC com todos cuidados pedagógicos. Ainda, nas palavras de Mercadante "[...] nós vamos ter computador na escola, vamos ter TIC na escola, e o professor no Brasil vai ter todas as chances de se modernizar, se quiser [...]".

A partir desses textos, acreditamos que os objetivos da política do tablete seriam voltados para práticas pedagógicas supostamente enriquecidas pela articulação a recursos digitais. Esse discurso aproxima-se muito daqueles presentes nos textos de órgãos transnacionais. Nele, as TIC são vistas como um sinônimo de desenvolvimento e aprimoramento das práticas escolares. Não podemos definir o que o ministro compreende como cuidados pedagógicos (aqueles tomados na distribuição do tablete), mas inferimos aqui

\footnotetext{
${ }^{11}$ http://www.imf.org/external/about.htm

${ }^{12} \mathrm{http}: / /$ www.imf.org/external/np/exr/facts/globstab.htm

${ }^{13} \mathrm{https}$ ///pt.khanacademy.org/about

${ }^{14}$ https://www.youtube.com/watch?v=wLyz0xUGcJ8
} 
que, entre outros possíveis significados, isso possa se relacionar à formação docente. $\mathrm{O}$ Proinfo promove ações formativas descentralizadas, as quais mencionamos acima. Por isso, trouxemos esse tema para nossas entrevistas no sentido de compreender também os sentidos que professoras e professores atribuíram às suas experiências formativas.

\subsection{Contexto de prática: conjunto de dados}

Apresentaremos nessa subseção aspectos voltados ao contexto de prática. Os dados advêm de relatos de professoras de língua inglesa de escolas públicas de diferentes regiões do Estado do Paraná, em entrevistas orais com 10 professoras, com cerca de 30 minutos de duração, realizadas via Skype entre 20 e 30 de novembro de 2015, gravada em áudio e transcrita.

O roteiro para a entrevista (anexo A) levou em conta respostas a um questionário aberto que havia sido enviado a docentes de todo o Estado do Paraná, de diferentes disciplinas. Nesse momento, perguntas mais voltadas aos contextos micro dos participantes foram feitas, bem como perguntas sobre formação, avaliação da política, usos e qualidade do tablete e percepções sobre TIC na sociedade/escola. Das entrevistas participaram somente docentes de língua inglesa. Essa escolha se deve aos interesses de formação inicial e continuada dos autores deste trabalho, bem como à linha de pesquisa em se inserem, intitulada "Ensino/aprendizagem e formação do professor de língua estrangeira".

\subsection{Categorias preliminares}

Ao nos utilizarmos da Grounded Theory para tratarmos dos dados, identificamos 21 categorias., por meio de processo de codificação sugerido por Charmaz (2006), para quem, a codificação na Grounded Theory é um momento em que os dados são separados, organizados e sintetizados. A partir disso, notas analíticas (chamadas memos) são feitas sobre aspectos que emergem das interpretações do pesquisador no sentido de permitir comparações constantes dos dados. As categorias criadas a partir de nosso olhar se referem a três eixos identificados em nossas análises, a saber: a) constrangimentos no uso do tablete educacional; b) possibilidades e c) questionamentos da política. Apresentaremos abaixo algumas categorias de maneira mais detalhada bem como traremos excertos que as compõem. Nossas entrevistadas ${ }^{15}$, nomeadas daqui em diante de P10 a P1.

O grupo constrangimentos no uso do dispositivo é composto pelas seguintes categorias: a) qualidade do dispositivo; b) características técnicas do dispositivo; c) obsolescência; d) formação; e) tempo necessário para uso do dispositivo e outras TIC na escola; f) cultura de uso das TIC; g) curso do tablete: escopo; h) curso do tablete: oferta; j) outros aspectos formativos. Ainda no grupo dos constrangimentos, em se tratando da articulação do tablete com outras TIC e aspectos presentes na escola (o que prevê textos representativos da política), temos as seguintes categorias: k) qualidade das TIC; 1) características técnicas das TIC; e m) obsolescência; n) conectividade; o) demanda quantitativa e TIC; p) infraestrutura e TIC; q) comunidade escolar; r) manutenção de TIC; e s) suporte de uso de TIC. É importante salientar que as categorias sobre constrangimentos podem nos indicar razões pelas quais 66,4 das respondentes do questionário online não utilizarem o tablete embora o tenham recebido. Já nas entrevistas, somente 3 das 10 entrevistadas utilizam ou já utilizaram o dispositivo.

\footnotetext{
${ }^{15}$ Considerando que a maior parte das contribuições foi de mulheres em nossa coleta de dados, nos referimos a todas as respondentes e entrevistadas no feminino.
} 
A categoria características técnicas do dispositivo (categoria b) é uma dos presentes no grupo constrangimentos no uso do dispositivo. Trouxemos tal categoria para essa análise preliminar por 8 das 10 colaboradoras terem mencionado esse fator como um constrangimento na realização da política do tablete. A percepção que segue é uma das que a compõem:

[...] o tablete também, ele não tem memória suficiente. Às vezes nem pra rodar muita coisa. Ele não tem conexão HDMI... não, HDMI ele tem... ele não tem conexão USB, entrada USB... aí os professores, alguns diziam pra mim: "ah, então não vou poder colocar meu pen drive, não sei o quê! " Parece que tudo sempre falta alguma coisa. (P10)

A categoria conectividade (categoria n) também surgiu a partir de percepções recorrentes nas entrevistas (em 8 de 10 entrevistas), como externa P9:

[...] mas nem sempre o nosso laboratório... nossa internet é adequada... Há muita oscilação, há muita coisa nesse sentido. Daí a gente acaba deixando, né, por isso. Temos um laboratório bem... formado com vários computadores, assim, mas a internet ainda não é de acordo.

A oferta do curso do tablete (categoria h) surgiu em 5 das 10 entrevistas, e foi problematizada por excertos como o de P8:

[...] Mas acho que a gente precisava ter feito treinamento, pra todos que receberam deveriam ter tido acesso ao treinamento. Teve, mas como eu no dia sempre tinha aula, tinha que ir no dia que não tinha aula, eu nunca fiz treinamento. Até vejo que os que fizeram acabaram usando, e ainda tem alguns até usando, né? Mas muito pouco.

A cultura de uso das TIC (categoria f), uma categoria que toca em questões voltadas para nativos e imigrantes digitais emergiu a partir de aspectos presentes em 8 das 10 entrevistas.

No caso das TVs, de fato, estão extremamente ultrapassadas, nessa questão até, apesar de estarem ali montadas, mas então, desses arquivos que muitas vezes não lê, toda essa questão aí, o despreparo de muitos profissionais, principalmente não querendo ser discriminatória, mas até assim dos professores um pouco mais velhos, um pouco mais antigos que não gostam do uso de tecnologias, então eles não estão preparados, já não gostam muito e já não tem um certo preparo, vão falar: "ai, eu já nem sei mexer nisso, não vou ficar quebrando a cabeça com isso, perdendo tempo e tal". (P6).

A partir desses excertos e categorias, compreendemos que os constrangimentos no uso do tablete assumem vários contornos na realização da política do tablete educacional. No grupo possibilidades, existem duas categorias, a saber: a) possíveis usos em caso de qualidade superior do tablete educacional - categoria que surgiu em face do grande número de colaboradoras que não usavam o dispositivo (3 entre 10 entrevistadas) -; e b) descrição de aplicações práticas do dispositivo. Entre os recorrentes relatos de uso do tablete educacional, (aspecto mencionado em 7 das 10 entrevistas) a categoria a) referente aos possíveis usos em caso de qualidade superior do tablete educacional apresenta alternativas como a de P4:

Olha, eu acho que o tablete, se nós tivéssemos, por exemplo, uma boa internet na escola que conectasse e tal [...] o aluno quer escrever uma palavra, ele não sabe, às vezes ele não tem um dicionário, se eu tivesse o tablete funcionando, eu dou tablete pra ele, ele pesquisa na hora. Ele sana 
aquela dúvida na hora ou então qualquer coisa. Um mapa, por exemplo... quero falar a alguma coisa que remete ao mapa, eu não tenho mapa, até que vou mandar meu aluno buscar um mapa lá na salinha que tem que buscar e achar alguém pra arrumar esse mapa pra ele, e ele voltar, terminou minha aula, ao passo que se tivesse tablete ali, eu posso achar o mapa na hora, mostrar aquilo pro aluno no mapa, o aluno viu, pronto. Sabe? Eu acho que ele seria muito útil. E outra coisa que eu acho que eles deveriam pensar seria uma forma de criar um sistema, alguma coisa em que os cadernos de chamada fossem utilizados através dos tabletes, criar um caderno de chamadas virtual.

Nesse grupo, as professoras apontam possíveis usos que poderiam ser feitos do tablete educacional caso sua qualidade fosse superior. É importante salientar que tais usos também dependeriam de outros aspectos, como aponta $\mathrm{P} 4$ no início do excerto ao se referir à conexão com a Internet.

A única categoria presente no grupo questionamentos da política denomina-se escolha do dispositivo. Nessa categoria, todas as professoras sugeriram a troca do dispositivo. As duas recomendações com maior incidência são sobre a troca do tablete por notebooks ou por tabletes melhores, como é possível verificar no discurso de P3:

[...] pra baixar um aplicativo, eu tenho que criar um login, uma senha e tudo mais. Pelo sistema de tecnologia que ele tem, né? Isso limita um pouco. Por exemplo, um editor de texto, eu preciso baixar e instalar no aparelho pra que ele funcione. Aí considerando essas questões, ele acaba sendo limitado. Você comparar com um netbook que serve tanto quanto, ele já vem com os recursos disponíveis instalados.

Já P2 também parece questionar a política, não sugerindo a troca do tipo de dispositivo distribuído por outra TIC, mas sim por um tablete de qualidade superior:

Poderia até ser o tablete, mas com maior potência, né? Com mais recursos, né? Como temos hoje nos Iphones, Ipods, Ipads, né, porque hoje se você tiver um (...) se você tiver um daquele ali, aposto que vai preferir usar o celular dele mesmo. Todos eles têm celulares de grande qualidade, né?

Até o momento, a partir de nossas entrevistas, bem como de nosso questionário online, compreendemos que a política do tablete nos contextos participantes de nossa pesquisa não tem sido realizada a contento sob o olhar das professoras participantes. A viabilização de uma melhor realização da política nos parece se relacionar a vários aspectos que talvez não tenham sido devidamente articulados às ações da política.

Preliminarmente, acreditamos que a política de distribuição de tabletes educacionais deveria ser melhor planejada em relação a outras políticas de inserção de TIC, manutenção e formação, não só de professores como também de outros sujeitos inseridos na comunidade escolar, uma vez que a distribuição dos dispositivos por si só não pôde de promover práticas de ensino e aprendizagem significativas nos contextos analisados a partir do dispositivo. Os dados indicam que os constrangimentos no uso da ferramenta assumem diferentes contornos, o que pode indicar a falta de articulação entre ações governamentais, como de manutenção e formação, para a realização da política do tablete.

\section{Conclusões}


O questionário online indicou que dos professores respondentes, $66,4 \%$ não utilizam o tablete embora o tenham recebido. A criação preliminar de categorias a partir de uma perspectiva fundamentada nos dados nos permitiu identificar os principais usos e constrangimentos em relação à política do tablete educacional presentes nos discursos de professoras que colaboraram com a pesquisa. Os objetivos da política apontados pelo ministério da educação e FNDE parecem não ir ao encontro das percepções das colaboradoras dessa pesquisa. Por textos oficiais, compreendemos que o tablete deveria ser articulado a outras TIC, ao cotidiano escolar, à formação do professor, infraestrutura entre outros aspectos identificados nas categorias. Alguns dos usos empreendidos estão relacionados a atendimentos individualizados em contexto hospitalar, criação de jogos e ensino de suas características técnicas a alunos. Embora reconheçamos o papel fundamental dos vários aspectos mencionados pelas professoras no uso do tablete, para nós, os principais problemas pareceram estar ligados às características técnicas do dispositivo, que parece não possuir especificações de hardware boas o suficiente para o uso em sala de aula.

\section{REFERENCIAS}

ABREU, C. C. F. de; NOGUEIRA, D. X. P. O uso dos tablets na educação: estudo comparativo entre uma escola pública e uma escola privada no Distrito Federal, 2013. Disponível em: http://bdm.unb.br/handle/10483/7861. Acesso em: 19 jun. 2015.

ABREU, K. C. K.; KRAEMER. K. História e usos da Internet. BOCC. Biblioteca On-line de Ciências da Comunicação, v. 2009, p. 01-09, 2009.

BALL, S. J.; MAGUIRE, M.; BRAUN, A. How schools do policy: policy enactment in secondary schools. Nova Iorque: Routledge, 2012.

BARCELOS, G. T. et al. Uso educacional de tablets: estudo de caso na formação inicial de professores de matemática. Renote: Revista Novas Tecnologias na Educação, Porto Alegre, v. 11, n. 1, p.1-10, jul. 2013. Semestral. Disponível em: <http://seer.ufrgs.br/index.php/renote/article/view/41652/26422>. Acesso em: 16 jun. 2015.

BRAGA, D. B.. Tecnologia da informação e comunicação e novos letramentos. In: BRAGA, Denise Bértoli. Ambientes digitais: reflexões teóricas e práticas. São Paulo: Cortez, 2013.

BRASIL. Apresentação, 201-. $\quad$ Disponível em: http://www.fnde.gov.br/portaldecompras/index.php/produtos/tablet-educacional/tablet-educacionalapresentacao. Acesso em: 19 jun. 2015

BRASIL. Decreto $\mathbf{n}^{\mathbf{0}}$ 5.542. Disponível em: http://www.planalto.gov.br/ccivil_03/_Ato20042006/2005/Decreto/D5542.htm. Acesso em: 22 abril. 2016

BRASIL. Preços Registrados, 201-. Disponível em: http://www.fnde.gov.br/portaldecompras/index.php/produtos/tablet-educacional/tablet-educacionalprecos-registrados. Acesso em: 22 jun. 2015

BRASIL. Pregões Anteriores, 201-. Disponível em: http://www.fnde.gov.br/portaldecompras/index.php/produtos/tablet-educacional/tablet-educacionalpregoes-anteriores. Acesso em: 19 jun. 2015

BRASIL. Programa Banda Larga nas Escolas (PBLE), 201-. Disponível em: http://www.fnde.gov.br/programas/programa-nacional-de-tecnologia-educacional-proinfo/proinfoprograma-banda-larga-nas-escolas-pble. Acesso em: 22 jun. 2015. 
BRASIL. Programa um computador por aluno (PROUCA), 201-. Disponível em: http://www.fnde.gov.br/programas/programa-nacional-de-tecnologia-educacional-proinfo/proinfotablets. Acesso em: 22 jun. 2015

BRASIL. Projeto um computador por aluno (UCA), 201-. Disponível em: http://www.fnde.gov.br/programas/programa-nacional-de-tecnologia-educacional-proinfo/proinfoprojeto-um-computador-por-aluno-uca. Acesso em: 22 jun. 2015

BRASIL. Tablets, 201-. Disponível em: http://www.fnde.gov.br/programas/programa-nacional-detecnologia-educacional-proinfo/proinfo-tablets. Acesso em: 26 maio. 2015

BRIGGS, A.; BURKE, P. Uma história social da mídia: de Gutenberg à Internet. Tradução: DIAS, M. C. P. Rio de Janeiro: Jorge Zahar Ltda, 2006.

CHARMAZ, K. Constructing Grounded Theory: a practical guide through qualitative analysis. Londres: SAGE Publications, 2006.

CRUZ, A. G. da; NERI, D. F. de M. A inserção de tablets em escolas da rede pública estadual na cidade de Petrolina-PE: uma percepção dos educadores educandos. Revista de Educação do Vale do São Francisco - Revasf, Petrolina, v. 4, n. 6, p.06-26, dez. 2014.

GIACOMAZZO, G. F.; FIUZA, P. J. A implantação do tablet educacional na perspectiva dos professores. Revista Tecnologias na Educação, v. 11, p. 1-10, 2014.

LEMOS, A. Ciber-Cultura-Remix. In: Denize Correia Araújo. (Org.). Imagem. (Ir) Realidade, Comunicação e Cibermídia. Porto Alegre: Editora Sulina, 2006, v. 1, p. 52-65.

LIBÂNEO, J. C. Politicas educacionais no Brasil: desfiguramento da escola e do conhecimento escolar. Cadernos de Pesquisa (Fundacao Carlos Chagas), v. 46, p. 38-62, 2016.

NASCIMENTO, U. L. S. do. FREIRE, M. L.de F. Um relato da experiência da capacitação de professores para o uso do tablet educacional. 2014. 29f. Trabalho de Conclusão de Curso (Especialização em Fundamentos da Educação: Práticas Pedagógicas Interdisciplinares) Universidade Estadual da Paraíba, Itabaiana, 2014.

SELWYN, N. O uso das TIC na educação e a promoção de inclusão social: uma perspectiva crítica do Reino Unido. Educ. Soc., Campinas, v. 29, n. 104, p. 815-850, Out. 2008

PIERRE, Lévy. A nova relação com o saber. In: PIERRE, Lévy. Cibercultura. Tradução de Carlos Irineu da Costa. São Paulo: Editora 34, 1999.

PRENSKY, M.: Digital Natives Digital Immigrants. In: PRENSKY, M. On the Horizon. NCB University Press, Vol. 9 No. 5, outubro, 2001.

NEVES, A. M.; CARDOSO, R. C. SIMPÓSIO HIPERTEXTO E TECNOLOGIAS NA EDUCAÇÃO, 4, 2013, Pernambuco. Os desafios do uso do tablet pelos professores do ensino médio das escolas públicas do Distrito Federal. [Pernambuco]: Ufpe, 2013. 22 p. Disponível em: <http://www.nehte.com.br/simposio/anais/simposio2013.html>. Acesso em: 12 jun. 2015.

UNESCO. Brasil no rumo da inclusão, 2008. Disponível em: http://unesdoc.UNESCO.org/images/0015/001585/158502por.pdf. Acesso em: 26 maio. 2015.

REAL, L. M. C.; TAVARES, M. N. R.; PICETTI, J. dos S. WORKSHOPS DO CONGRESSO BRASILEIRO DE INFORMÁTICA NA EDUCAÇÃO, 2., 2013, Campinas. Formação de Professores para o Uso Educacional de Tablets no Ensino Médio: possíveis mudanças na prática pedagógica. Campinas: Universidade Estadual de Campinas Campinas, 2013. 9 p. Disponível em: <http://www.br-ie.org/pub/index.php/wcbie/article/view/2729/2383>. Acesso em: 21 jun. 2015. 
*Obrigatório

Parte 1 - informações pessoais

Perfil:

1. Cidade em que leciona $*$

2. Gênero *

C Feminino

C Masculino

3. Idade: assinale a faixa correspondente à sua idade *

- 18 a 20

- 21 a 25

- 26 a 30

- 31 a 35

- 36 a 40

- 41 a 45

- 46 a 50

- 51 a 55

- 56 a 60

- 61 ou mais

Parte 2 - perfil e prática docentes

4. Por favor, identifique a sua formação:

- Г Graduação

○ Г Pós-doutorado

○ Г Doutorado

○ Г Mestrado

- Г Formação PDE

○ Г Especialização

- Г Outro:

5. Anos de experiência em ensino: *
C. Menos de um ano
C 1 a 5 anos
6 a 10 anos
C 11 a 15 anos
C 16 a 20 anos
C 21 a 25 anos 


$$
\begin{array}{ll}
\circ & 26 \text { a } 30 \text { anos } \\
\circ & 31 \text { a } 35 \text { anos } \\
\circ & \text { Mais de } 35 \text { anos }
\end{array}
$$

6. Anos de experiência em ensino no setor público: *

- Menos de um ano

- 1 a 5 anos

- 6 a 10 anos

- 11 a 15 anos

- 16 a 20 anos

- 21 a 25 anos

- 26 a 30 anos

- 31 a 35 anos

- Mais de 35 anos

7. Número aproximado de horas-aula dadas por semana no setor público neste ano: *
10 horas
20 horas
C 30 horas
C. 40 horas
50 horas
C. 60 horas
Mais de 60 horas

8. Número médio de alunos por turma: *
- 5 a 10
- 11 a 15
- 16 a 20
- 21 a 25
- 26 a 30
- 31 a 35
- 36 a 40
- 41 ou mais
9. Perfil socioeconômico da maioria dos alunos de sua (s) escola (s): *
- Classe A - acima 20 salários mínimos (R 14.500 ou mais)
- Classe B - 10 a 20 salários mínimos (de R $\$ 7.250,00$ a $\mathrm{R} \$ 14.499,99$ )
- Classe C - 4 a 10 salários mínimos (de $\mathrm{R} \$ 2.900,00$ a $\mathrm{R} \$ 7.249,99$ )
- Classe D - 2 a 4 salários mínimos (de $\mathrm{R} \$ 1.450,00$ a $\mathrm{R} \$ 2.899,99$ )
- C Classe E - até 2 salários mínimos (até $\mathrm{R} \$ 1.449,99$ ) 
10. Qual disciplina você ministra? *

$\circ$ Arte

○Г Biologia

○ Г Educação Física

○ Г Ensino Religioso

○ Г Filosofia

○ Г Física

○ $Г$ Geografia

○ Г Língua Inglesa

○ $\square$ Língua Portuguesa

○ Г Outra língua estrangeira moderna

○ Q Química

- $\quad$ Sociologia

Parte 3 - informações sobre o tablete educacional

11. Você faz uso do tablete educacional? *

C Sim

C Não

12. Se você respondeu NÃO, indique se nunca usou ou já usou e não usa mais:

- Nunca usei

- Usei, porém não uso mais

13. Se já usou, mas não usa mais, por favor, explique o porquê:

-1
-

14. Se sua resposta foi SIM para a pergunta 12, há quanto tempo usa o tablete educacional?

- 1 a 2 meses

- 3 a 4 meses

- 1 ano

- mais de 1 ano

15. Se sua resposta foi SIM para a pergunta 12, com que frequência você utiliza o tablete educacional?

1 vez por semana

2 vezes por semana

3 vezes por semana

Mais de 4 vezes por semana 
16. Avalie a qualidade técnica do tablete educacional para a prática pedagógica:

Muito bom

Bom

C Regular

C Ruim

17. Caso ocorra, selecione as opções relacionadas ao uso do seu tablete educacional

$\Gamma$ Acessar materiais de apoio para planejamento de aulas

$\Gamma \quad$ Redigir plano de aula

ᄃ Fazer cursos online

$\Gamma \quad$ Fazer chamada ou anotações em sala

$\ulcorner\quad$ Utilizar o Portal do Professor do MEC

Г Outro:

18. Quantos cursos de formação você fez para a utilização do tablete educacional ofertados pelo Estado do Paraná? *
C 1
C 2
C Mais de 3
Cenhum

19. Caso tenha feito o (s) curso (s), como você avalia o (s) curso (s) de formação para o tablete educacional ofertado (s) pelo Estado do Paraná?

- Muito bom

Bom

C Regular

C Ruim

20. Por favor, leia as afirmações abaixo e assinale sua opinião *

Concordo $\begin{gathered}\text { Concordo } \\ \text { parcialmente }\end{gathered}$ Discordo $\begin{gathered}\text { Discordo } \\ \text { parcialmente }\end{gathered} \quad \begin{gathered}\text { Não sei } \\ \text { responder }\end{gathered}$
Acho que o
tablete
educacional
me ajuda na
prática
profissional
Sinto que
é possível
integrar o
tablete
educacional
ao cotidiano
escolar e ao
uso de outras
novas 


\begin{tabular}{|c|c|c|c|c|c|}
\hline & Concordo & $\begin{array}{c}\text { Concordo } \\
\text { parcialmente }\end{array}$ & Discordo & $\begin{array}{c}\text { Discordo } \\
\text { parcialmente }\end{array}$ & $\begin{array}{l}\text { Não sei } \\
\text { responder }\end{array}$ \\
\hline tecnologias & & & & & \\
\hline $\begin{array}{l}\text { A escola } \\
\text { disponibiliza } \\
\text { outras novas } \\
\text { tecnologias } \\
\text { para } \\
\text { utilização } \\
\text { junto com o } \\
\text { tablete } \\
\text { educacional }\end{array}$ & $\mathrm{C}$ & $\mathrm{C}$ & $\mathrm{C}$ & $\mathrm{C}$ & $\mathrm{C}$ \\
\hline $\begin{array}{l}\text { Minha escola } \\
\text { oferece } \\
\text { suporte } \\
\text { técnico para o } \\
\text { uso de novas } \\
\text { tecnologias }\end{array}$ & $\mathrm{C}$ & $\mathrm{C}$ & $\mathrm{C}$ & $\mathrm{C}$ & $\mathrm{C}$ \\
\hline $\begin{array}{l}\text { Para mim, } \\
\text { preparar aulas } \\
\text { no tablete } \\
\text { educacional é } \\
\text { mais prático e } \\
\text { interessante } \\
\text { do que } \\
\text { utilizar outras } \\
\text { tecnologias }\end{array}$ & $\mathrm{C}$ & $\mathrm{C}$ & $\mathrm{C}$ & $C$ & $\mathrm{C}$ \\
\hline $\begin{array}{l}\text { Considero o } \\
\text { (s) curso (s) } \\
\text { de formação } \\
\text { ofertado (s) } \\
\text { pelo estado } \\
\text { para o uso do } \\
\text { tablete } \\
\text { educacional } \\
\text { suficiente (s) } \\
\text { para a minha } \\
\text { prática }\end{array}$ & $\mathrm{C}$ & $C$ & $\mathrm{C}$ & $\mathrm{C}$ & $\mathrm{C}$ \\
\hline $\begin{array}{l}\text { Considero a } \\
\text { utilização do } \\
\text { tablete } \\
\text { importante } \\
\text { para a minha } \\
\text { prática }\end{array}$ & $\mathrm{C}$ & $C$ & $\mathrm{C}$ & $C$ & $\mathrm{C}$ \\
\hline $\begin{array}{l}\text { Meu } \\
\text { tablete nunca } \\
\text { apresentou } \\
\text { defeitos }\end{array}$ & $C$ & $\mathrm{C}$ & $\mathrm{C}$ & $\mathrm{C}$ & $\mathrm{C}$ \\
\hline O suporte & $C$ & C & $\mathrm{C}$ & C & $C$ \\
\hline
\end{tabular}




\begin{tabular}{|c|c|c|c|c|c|}
\hline & Concordo & $\begin{array}{c}\text { Concordo } \\
\text { parcialmente }\end{array}$ & Discordo & $\begin{array}{c}\text { Discordo } \\
\text { parcialmente }\end{array}$ & $\begin{array}{l}\text { Não sei } \\
\text { responder }\end{array}$ \\
\hline $\begin{array}{l}\text { técnico para o } \\
\text { conserto do } \\
\text { tablete é } \\
\text { rápido e } \\
\text { eficiente }\end{array}$ & & & & & \\
\hline $\begin{array}{l}\text { Vejo que o } \\
\text { uso do tablete } \\
\text { educacional é } \\
\text { uma prática } \\
\text { recorrente } \\
\text { entre meus } \\
\text { colegas de } \\
\text { trabalho }\end{array}$ & $C$ & $\mathrm{C}$ & $\mathrm{C}$ & $\mathrm{C}$ & $C$ \\
\hline $\begin{array}{l}\text { Sinto que } \\
\text { meu trabalho } \\
\text { é enriquecido } \\
\text { pelo uso do } \\
\text { tablete }\end{array}$ & $\mathrm{C}$ & $C$ & $\mathrm{C}$ & $\mathrm{C}$ & $\mathrm{C}$ \\
\hline $\begin{array}{l}\text { Sinto que a } \\
\text { escolha do } \\
\text { tablete, ao } \\
\text { invés de outra } \\
\text { nova } \\
\text { tecnologia, } \\
\text { foi acertada } \\
\text { para o meu } \\
\text { contexto de } \\
\text { trabalho }\end{array}$ & $\mathrm{C}$ & $C$ & $C$ & $C$ & $C$ \\
\hline $\begin{array}{l}\text { Tenho } \\
\text { conhecimento } \\
\text { sobre os } \\
\text { recursos } \\
\text { didáticos } \\
\text { disponíveis } \\
\text { no Portal do } \\
\text { Professor }\end{array}$ & $C$ & $C$ & $C$ & $\mathrm{C}$ & $C$ \\
\hline $\begin{array}{l}\text { Tenho tempo } \\
\text { suficiente } \\
\text { para preparar } \\
\text { aulas no } \\
\text { tablete } \\
\text { educacional }\end{array}$ & $C$ & $C$ & $\mathrm{C}$ & $\mathrm{C}$ & $C$ \\
\hline $\begin{array}{l}\text { Possuo } \\
\text { conhecimento } \\
\text { suficiente } \\
\text { para preparar } \\
\text { aulas no }\end{array}$ & $\mathrm{C}$ & $\mathrm{C}$ & $\mathrm{C}$ & $\mathrm{C}$ & $\mathrm{C}$ \\
\hline
\end{tabular}




Concordo $\begin{gathered}\text { Concordo } \\ \text { parcialmente }\end{gathered}$ Discordo $\begin{gathered}\text { Discordo } \\ \text { parcialmente }\end{gathered} \begin{gathered}\text { Não sei } \\ \text { responder }\end{gathered}$

tablete
educacional
Meu contexto
de trabalho
possibilita
acesso à
internet banda
larga e
conexão wifi
de qualidade
nos locais
onde isso é
necessário
Caso
houvesse
novos cursos
para o uso do
tablete
educacional,
eu os faria
Já ouvi falar
sobre o
Programa Um
Computador
por Aluno
(PROUCA)
O Programa
Um
Computador
por Aluno
está
implementado
e funcionando
em minha
escola
acégostara de col

21. Você gostaria de comentar algo sobre o tablete educacional, seus usos e potencialidades? Aqui você inclusive pode comentar o porquê de fazer ou não fazer uso dele de maneira mais detalhada:

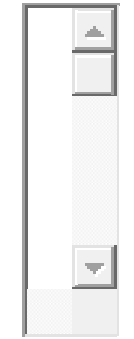

Car@professor@ de inglês, se você tem mais a dizer, deixe seu telefone, e-mail ou Skype para nos conceder uma breve entrevista. Essa informação é somente para o nosso uso e 
não será inclusa de maneira alguma nos dados. Mais uma vez, agradecemos pela sua colaboração!

Insira seu telefone, e-mail ou Skype:

\section{Anexo B}

A política do tablete educacional no ensino de inglês nas escolas públicas do Paraná

\section{Perguntas gerais sobre políticas de inclusão:}

\section{Roteiro de entrevista}

1- Na sua opinião, qual o papel das tecnologias digitais nas escolas?

2- Como políticas de inserção de TIC acontecem no ensino de sua disciplina? Isto é satisfatório?

3- O que você acha da escolha de distribuição do tablete educacional a professoras e professores de inglês? Você escolheria outra nova tecnologia?

4- Qual a sua relação com as novas tecnologias? O que elas propiciam a você?

5- Com que frequência você faz uso de novas tecnologias na escola? Por quê?

6- Qual a relação de seus alunos com as novas tecnologias? O que a escola propicia a eles?

\section{Potencialidades do tablete educacional:}

7- Você usa o tablete educacional? Por quê?

Caso ocorra: Quais usos do tablete você faz? Por quê?

Caso respondam que não usam pela qualidade do aparelho: Quais usos você faria do tablete se sua qualidade fosse superior? Quais objetivos teriam esses usos?

8- O que o tablete propicia ou deveria propiciar a você enquanto professora ou professor de língua inglesa? Quais seriam formas de uso interessantes para a sua prática pedagógica?

\section{Articulação com outras TIC:}

9- Sua escola possui outras novas tecnologias para integrar ao tablete? (ex: notebooks, datashows, tela interativa, lab do ProInfo, banda larga, wi-fi etc). Como você avalia a qualidade técnica dessas tecnologias?

10- Caso você pudesse substituir a distribuição do tablete por outros benefícios para a escola (não necessariamente TIC), o que você faria?

\section{Suporte técnico e de uso de tecnologias:}

11- Como ocorre a manutenção de novas tecnologias em sua escola?

12- Com que frequência sua escola participa de editais para ser contemplada por políticas de inserção de TIC? Você possui conhecimento sobre esses processos?

\section{Formação:}


13- Você fez o curso para uso do tablete educacional? Se sim: como o avalia? Mudaria algo no curso? O quê? Se não: por quê?

14- Você tem algo a mais para dizer sobre a política do tablete educacional e seu impacto nas aulas de língua inglesa na escola pública? 